\begin{tabular}{l}
$\begin{array}{c}\text { Yanbu Journal } \\
\text { of }\end{array}$ \\
$\begin{array}{l}\text { Engineering } \\
\text { and Science }\end{array}$ \\
\hline \hline ISSN: $1658-5321$
\end{tabular}$\quad$ Vol. 13, December $2016(1438 \mathrm{H})$

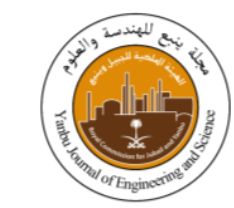

\title{
A MULTISINK ENERGY-EFFICIENT ROUTING PROTOCOL FOR WIRELESS BODY AREA NETWORK
}

\author{
Tarneem O. Barayyan, Arshpreet Kaur, Shilpa Shilpa \\ Department of Electrical \& Computer Engineering, University of Waterloo, Canada \\ E-mail:tamen.o@gmail.com
}

\begin{abstract}
Rapid advancements in wireless sensor network have significantly supported the wireless body area networks (WBAN). In WBAN, especially in medical application, the energy efficiency of the sensor nodes is critical in the Intra-body communication level. In this case, the communication occurs between the sensor nodes (placed inside the human tissue) and sink node (placed on the human skin). Thus, replacing the battery of these sensor nodes is challenging. Several studies in Intra-body communication have focused on reducing the energy consumption by decreasing the distance required to transmit the sensed data. However, the stability of the system (overall lifetime of the system) is not achieved due to the variation in the lifetime of the sensor nodes. Herein, some sensor nodes act as relay nodes. These relay nodes are responsible for sensing, receiving, and aggregating the sensed data from the neighboring sensor nodes, and further sending it to the sink node. The present study describes a unique approach to achieving an energyefficient routing protocol that guarantees a prolonged lifetime of the sensor, thereby stabilizing the system. Moreover, the peer-to-peer communication between the sensor and sink nodes is also investigated with respect to the mobility model. In conclusion, this study aims to remove the burden from sensor nodes by using multiple sink nodes in order to achieve the shortest distance of communication between the sensor and sink nodes, which could prolong the lifetime of sensor nodes and the overall stability of the system.
\end{abstract}

Keywords: Wireless Body Area Network (WBAN), energy efficiency, routing protocols, sink nodes.

\section{INTRODUCTION}

Wireless Body Area Network (WBAN) is one of the Wireless Sensor Network (WSN) application utilized in the medical field. WBAN is a short range network, in which, sensor nodes are placed inside the human body. These sensor nodes are small and lightweight and used to sense the vital signs such as the heart rate, oxygen level, and blood. These sensors forward the sensed data to the sink node, which is commonly placed on the skin surface. These sink nodes collect the data from all the sensors and pass it to the coordinator node, which acts as a gateway for WBAN. Subsequently, the coordinator nodes send the data to the base station, which can either be a PC, a smartphone, or a laptop that is used by the doctor to monitor the patients' health status. Thus, body sensors have been introduced to use the human body as a carrier for transmitting wireless signals $[1,2]$. Two main types of communications occur within the human body, electromagnetic waves and ultrasound waves. A large portion of the human body is comprised of water, which allows the ultrasound waves to propagate 
easily. However, for the electromagnetic waves, two types of sensors can be placed in the human body: capacitive coupling and galvanic coupling. The latter is the most commonly used sensor as it does not require grounding. Moreover, the defined frequency range for use within the human tissues is $100-500 \mathrm{kHz}$ [3]. The WBAN routing protocol is categorized into Intra-body and Inter-body communications [4]. The Intrabody represents the communication between the sensors and sinks, whereas the Inter-body represents that between the sink and coordinator nodes. However, the routing protocol in Intra-body communication experiences several challenges with respect to energy efficiency. Recently, several articles have introduced various routing approaches between the sink and sensors to maximize the network lifetime and stability. One of these studies focused on the effect of sink node position for saving energy and proposed an optimal position to minimize the distance [5]. Forwarders, acting as relay nodes for neighboring sensors, are typically those that receive, aggregate, and transmit the data to the sink $[4,6]$. The approach mentioned above prevents the formation of hotspots by homogeneous utilization of energy from each node. The two approaches, multihop and forwarder, introduced for the Intra-body communication routing protocol considers the probabilities of changes in the human body postures [8]. In these approaches, the sink node is fixed and placed on the chest, and all the measurements are recorded with respect to the position of the sink node. In the multihop approach, the sensor nodes sense data as well as aggregate the received data from other sensor nodes and send the data to the nearest relay node, which subsequently forwards it to the sink node. As a result, the sensor nodes that act as relay nodes are over- burdened, and their energy would exhaust rapidly. On the other hand, the forwarder approach uses a different concept of relay nodes, where the role is divided among all the sensor nodes equally. Thus, no sensor nodes will be under heavy load for a prolonged period.

\section{EXPERIMENTAL}

\subsection{GENERAL}

\subsubsection{Current Scenario and Drawbacks}

In Intra-body communication, the routing is performed by sending data to the sink node, which is responsible for collecting the data from sensors and transmitting to the coordinator node. The current research is focused on utilizing only one sink node. Several investigators have attempted to achieve the shortest distance routing protocol, including the multihop approach and optimal position of the sink node, in order to reduce the energy consumed during the communication process (i.e. sending the sensed data). Consequently, the sink node is burdened with multiple tasks of gathering the data from all nodes, calculating the varied distance because of movements, and prioritizing the queued data to forwarding, thereby needing a large storage area for all the data. The mobility model is known to play a major role in simulating WBAN with respect to the altered distance. The sensor nodes located farther can transfer data either by finding other sensors that act as relay nodes or by passing the data directly to the sink node. Thus, these relay nodes consume excessive energy due to the high communication process, thereby decreasing the lifetime of the sensor node.

\subsubsection{Proposed Resolution}

The proposed resolution uses multiple sink nodes to increase the lifetime of the sensor nodes in WBAN. These sensor nodes would 
connect to the nearest sink node and transmit the data over the shortest possible distance. The sensor nodes broadcast HELLO message when they need to transmit data to calculate the distance to the nearest sink node. In the proposed approach, communication occurs between the sensor and sink nodes, unlike previous approaches, in which, the sensor nodes can establish communication with the neighboring sensors that act as relay modes. This type of transmission causes no wastage of energy due to aggregation or reception of data from other sensors. The energy consumption is dependent on the transmission distance between the sink and sensor nodes. Due to body movement, the location of sensor nodes will change, and they will find the nearest sink node in an attempt to send data each time. Thus, the proposed approach will greatly alleviate the conservation of energy. The parameters such as residual energy and lifetime and stability of the network in the proposed approach should be compared with the concurrent methods.

\subsection{RELATED WORK}

WBAN routing protocol is divided into two categories, Intra-body and Inter-body communications [4]. The first category represents communication between the sensor nodes and sink nodes, while the second represents communication between the sink and coordinator nodes. The Intra-body communication encounters several challenges regarding energy efficiency. Recent studies introduced different routing approaches between the sink and sensor nodes to maximize the lifetime and stability of the network. One study proposed an optimal position for the sink node to minimize the distance and conserve energy [5]. Relay nodes are sensor nodes that receive data from neighboring sensor nodes, aggregate the data, and transmit it to the sink node $[4,6]$. The advantages of using mentioned approach are to prevent the formation of hotspots by homogeneous utilization of energy from each node. Initially, the sensor nodes send data, such as HELLO message, to the sink node and in turn receive information about parameters such node identity, location, velocity vector, and dissipated energy. Each time the data is delivered, the table is updated, and routing occurs through the most updated route. Although the approach mentioned above has better energy efficiency than the previous study, the relay nodes have to perform multiple tasks as described previously. Thus, the addition of more tasks to be performed by the sensors indicates increased burden, and hence, more energy consumption [7]. Furthermore, the impact of the position of the sink node on the network is analyzed [5]. Eight sensor nodes and a central sink node are employed to evaluate the system in body movement conditions. Since the human body exhibits different postures including sitting and standing, the movement results in altered distance between the sink and sensor nodes, which in turn results in changed network topology. The lifetime of a network or the energy consumption of the network is analyzed by placing the sink node at two positions: waist and center of the network. However, the disadvantage of this approach is overloading the sink node with data. Thus, single-hop routing approach is used to determine the position of the sink node for optimal energy consumption [7]. The optimal position for sink node is determined by placing it in various positions and then measuring the corresponding channel gain for all the links between the sink and sensor nodes. The channel gain is the difference between the received signal strength and transmitted power by sensor nodes. The average channel gain that is maximum is 
considered as the optimal position of the sink node. This highest value was reached when the sink node was placed at the center of the waist. Thus, the optimal position for the sink node is the waist center. The potential changes in the human body postures are also taken into account [8]. The ' $\mathrm{n}$ ' state Markovian model is used to determine the transition of the human body from one posture to another. However, the sink node is fixed and placed on the chest, and all the measurements are carried out with respect to this position. In addition, the multihop and forwarder approaches are compared. In the multihop approach, the sensor nodes send data to the relay nodes that receive, aggregate, and send the data to the sink node. In the forwarder approach, the relay nodes are selected for every round. These relay nodes receive and aggregate the data received from the nearby sensor nodes, thereby ensuring that none of the sensors are heavily loaded for a prolonged period. Thus, the forwarder approach is considered superior to the multihop routing approach in terms of lifetime and stability of the network.

\subsection{PROPOSED SYSTEM MODEL}

\subsubsection{Multisink Approach}

The multisink approach is based on a different concept as compared to the multihop and forwarder approaches. The aim of the approach is to achieve high stability of the system by reducing the energy consumption by the sensor nodes. This can be effectuated by eliminating the relay node and increasing the number of sink nodes. In this case, the sensor nodes would consume energy for transmitting the sensed data to the sink node. Thus, the network will achieve high stability and the lifetime of the sensor nodes would also increase. The multisink approach could be explained based on the following parameters:

\subsubsection{Network Module}

In the multisink approach, three sink nodes are placed at fixed locations instead of one sink node in order to reduce the communication between the sensors unlike the multihop and forwarder approaches. The sensors in the multisink approach do not act as relay nodes; thus, no energy is wasted due to aggregation. Moreover, the communication pattern in the multisink approach is peer-topeer (P2P), as each sensor node communicates directly with the sink node, eliminating the need for relay nodes. This P2P communication avoids any multitasking by sensor nodes and aids in increasing the lifetime of the system.

\subsubsection{Sensor Type}

The sensor nodes are homogeneous and placed under the human skin; whereas, the sink nodes are placed on the skin. All sensors have the same hardware module as well as the amount of initial energy (battery size). The initial energy is represented by Equation (1)

$$
\mathrm{E}_{\text {init }}=10,000 \text { Joules }(\mathrm{J})
$$

\subsubsection{HELLO Messages}

HELLO message is used in the multisink approach to identify the shortest route to sending the data from the sensor to the sink node. In this approach, the sensor node issues the HELLO message when there is data that needs to be transmitted. These HELLO messages calculate the distance between the sink and sensor nodes. On the other hand, in the multihop and forwarder approaches, the HELLO message is issued periodically by the sink node to all the sensor nodes. The sink node broadcasts the network information and the location of the relay nodes to all the sensor nodes via HELLO messages.

\subsubsection{Position of Sensor and Sink Nodes}

Table 1 represents eight sensor nodes and three sink nodes placed on a body. The sensor 
nodes are located within the muscular tissues while the sink nodes are located on the outer surface of the human skin. Sink node \#1 represents the node that is used in multihop and forwarder approaches, where all three sink nodes represent the multisink approach.

Table 1: Estimated Position Of Sensor and SinK NODES

\begin{tabular}{|c|c|}
\hline NODE & POSITION \\
\hline SENSOR NODE\#1 & BELLY \\
\hline SENSOR NODE \#2 & HEAD \\
\hline SENSOR NODE \#3 & LEFT SIDE OF CHEST \\
\hline SENSOR NODE \#4 & CHEST \\
\hline SENSOR NODE \#5 & LEFT WRIST \\
\hline SENSOR NODE \#6 & RIGHT WRIST \\
\hline SENSOR NODE \#7 & LEFT ANKLE \\
\hline SENSOR NODE\#8 & RIGHT ANKLE \\
\hline SINK NODE\#1 & CENTER OF CHEST \\
\hline SINK NODE\#2 & WAIST \\
\hline SINK NODE\#3 & HEAD \\
\hline
\end{tabular}

\subsubsection{Data Transmission to Nearest Sink Node}

The human body exhibits different postures including sitting, standing, and walking. For instance, consider a network structure where the sink node is placed on the chest and the sensor node is placed on the leg. Then, the distance between the sensor and sink nodes would be less in sitting the position as compared to that during the standing posture. Thus, the distance between the sink and sensor nodes varies according to the postures of the human body. In addition, mobility is also taken into account because energy consumption varies with respect to the distance between the sink and sensor nodes. In the proposed multisink approach, the sensor nodes find the nearest sink node by sending HELLO messages and estimate the distance with respect to the acknowledgment message from the sink sensors.

\subsubsection{System Stability and Lifetime}

In WBAN, the system stability and lifetime are critical; if one sensor node dies, the entire system is considered to be unstable. The stability represents the status of the entire network, i.e. residual energy of all the sensor nodes (overall lifetime of the system). The sensor node lifetime represents the lifetime of each sensor node (i.e. the duration of optimal function of the sensor node). This estimation is based on the point in time when each sensor node dies, i.e., the point when the energy of a sensor drops to zero. The lifetime of each sensor node is calculated, and thus, the overall lifetime of all sensor nodes is estimated (stability). The more symmetric the pattern of the time of death, the more stable is the system.

\subsection{SIMULATION AND THEORETICAL MODEL EVALUATION}

\subsubsection{Simulation Software}

In this study, MATLAB is used to represent the body area and the movement of the sensors. The total covered distance per sensor in all approaches is computed, followed by calculating the power consumed, and the remaining energy is calculated based on the equation in the previous section.

\subsubsection{Structural Model}

In this section, the specification of the system is defined for the multisink as well as the multihop and forwarder approaches. The assumptions are as follows:

Body Area, the body area is defined as $10 \times 10$ matrix, where there are eight sensor nodes. The distribution of the sensor nodes' initial locations and the sink nodes' fixed locations are specified with respect to each approach. Figure 1-3 demonstrate the assumption for multihop, forwarder, and multisink approaches, respectively. 
In the simulation, each node is represented using $(x, y)$ coordination with respect to its location inside the $10 \times 10$ matrix.

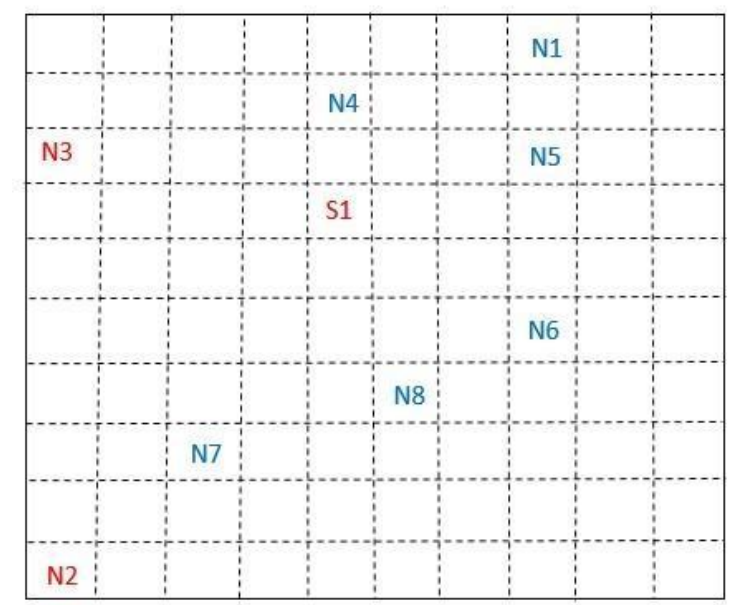

Fig. 1. 10×10 Body Area for Multihop Approach

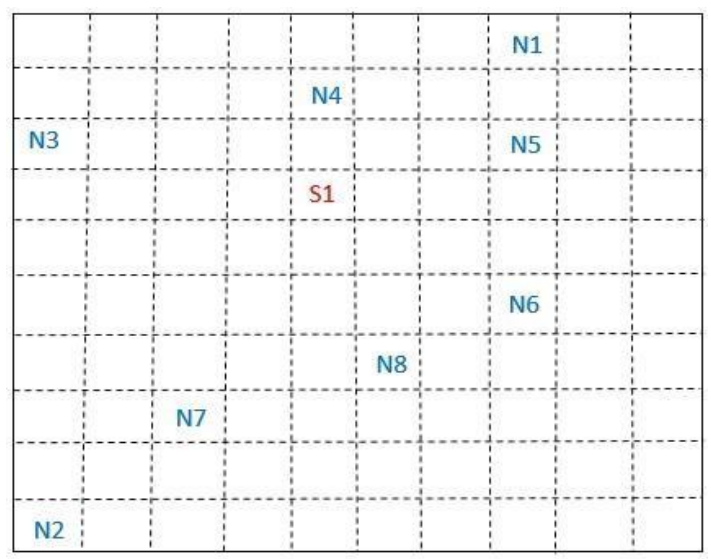

Fig. 2. $10 \times 10$ Body Area for Forwarder Approach

In Figure 1, S1 is the sink node, and N2 and $\mathrm{N} 3$ are acting as relay nodes. In the forwarder approach illustrated in Figure 2, S1 is the sink node, and the relay role is changing in every round; thus, all nodes act as relay nodes rotationally in every iteration. On the other hand, Figure 3 represents the multisink approach where three sinks, S1, S2, and S3, are used, and no relay role is assigned to the sensor nodes.

\subsubsection{Simulation Model}

This section explicates four case studies used to compare all the approaches from different perspectives.

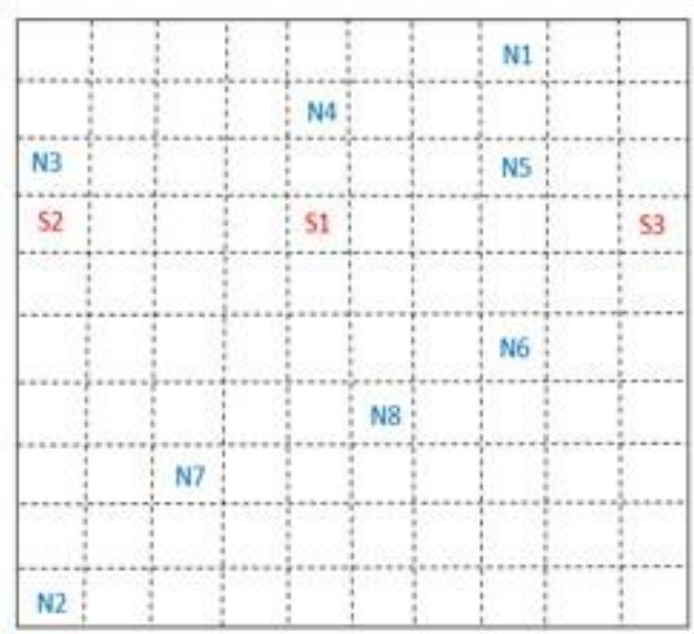

Fig. 3. 10×10 Body Area for Multisink Approach

\subsubsection{Case Study 1}

The HELLO message is evaluated with respect to the total number of communication units (communication unit here represents the transmitting and receiving process) consumed by each approach. HELLO messages are used differently and serve a varied purpose in each approach. In multihop and forwarder approaches, the HELLO message is broadcasted by the sensor node that harbors information about the relay node. The HELLO message in these two approaches follows a periodic pattern, in which, the sensor broadcasts the message every second. In the multisink approach, the message is sent by the sensor to the sink nodes in order to calculate the shortest route, and the sensor sends the HELLO message only when it has data for transmission, based on the assumption that the sensor will have data every 3 s. Thus, the HELLO message in the multisink approach is sent every $3 \mathrm{~s}$ followed by the transmission of the sensor data.

\subsubsection{Case Study 2}

Herein, the total distance covered by each sensor node to transmit the sensed data to the sink node is measured. Only one sensor node is presented in this case study that measures the distance covered during each transmission 
while sensor node N1 is moving. Equation (3) is used to define the total distance, and the results of the total distance covered by $\mathrm{N} 1$ for 10 iterations (in this case, iteration represents the time in s) for all approaches are shown in Table 1.

\subsubsection{Case Study 3}

In this case study, the residual energy is calculated for each approach using Equation (4). The energy consumption for case 2 is presented, wherein the sensor N1 moved 10 times. This case study shows that the energy level declines per movement. The residual energy is calculated based on the total energy consumed in the whole movement process. The aim is to measure the consumed energy with respect to the total distance obtained from case study 2 for each iteration.

\subsubsection{Case Study 4}

In this case study, the stability of the system, which is the overall lifetime of the system is assessed among all approaches. The stability is estimated by identifying the time of death of each sensor node (that represents the sensor node lifetime) in all the three approaches. The longer the sensor node lifetime, the more stability is achieved.

\subsubsection{Analytical Representation}

\subsubsection{Distance Calculation:}

The distance between the sensor and the sink or relay node can be calculated using Equations (2) and (3) as follows:

$$
\begin{gathered}
D=V\left[\frac{[(t 2-t 1)+(t 4-t 3)]}{2}\right] \\
D=\sqrt{\left(y_{2}-y_{1}\right)^{2}+\left(x_{2}-x_{1}\right)^{2}}
\end{gathered}
$$

In Equation (2), $\mathrm{D}$ denotes the distance between a sink and a sensor node, and $\mathrm{V}$ is the velocity of acoustic signals through the body tissue [9]. For instance, Table 2 presents different velocities of the propagation of the ultrasound signals through the body tissues. The proposed system uses acoustic waves to transfer the signal from the sensor to sink nodes. The speed of these acoustic waves varies in different media. These acoustic waves are primarily ultrasound waves traveling through the body tissues. In addition, we considered the two-way time of arrival to improve the synchronization of the time when the HELLO message is sent by the sensor and the time when the message is received by the sink node. However, the HELLO messages are essential to calculate the distance between the sensor and sink nodes. $\mathrm{t}$ is the time in seconds at which the HELLO messages are sent and received by the sensor and sink nodes. This equation is the theoretical representation of distance calculation, while Equation (3) represents the distance calculated for simulation (used in MATLAB simulation). $\mathrm{x}$ and $y$ in Equation (3) represent the coordinates of the node.

\section{TABLE 2: Velocity of Ultrasound SignaL THROUGH BODY TISSUE}

\begin{tabular}{|c|c|c|}
\hline Material & Density, D $\left[\mathrm{kg} / \mathrm{m}^{-3}\right]$ & $\begin{array}{l}\text { Speed } \\
{[\mathrm{m} / \mathrm{s}]}\end{array}$ \\
\hline Blood & 1060 & 1570 \\
\hline Bone & $1380-1810$ & 4080 \\
\hline Brain & 1030 & \\
\hline Fat & 920 & 1450 \\
\hline Kidney & 1040 & 1560 \\
\hline Liver & 1060 & 1570 \\
\hline Lung & 400 & \\
\hline Muscle & 1070 & \\
\hline Spleen & 1060 & \\
\hline Water & 1000 & \\
\hline
\end{tabular}


2.4.4.2 Residual Energy:

$\mathrm{Y}$ represents the energy consumption calculated based on the communication units, transmission, and reception of data by each sensor, as well as, the total distance covered to send the data to the sink node. The total energy consumed is proportional to the total distance covered for each communication unit. Equation (4) presents the energy consumption.

$$
{ }^{E} \text { consumed }=D \alpha+\beta
$$

Where $\mathrm{E}$ denotes the total energy consumed per communication unit (the communication unit could be the transmission of sensed data to the sink node), and D indicates the total distance covered to transmit the data from the sensor node to the sink node. Moreover, $\alpha$ and $\beta$ are constants; $\alpha$ denotes continuous friction losses in $\mathrm{J} / \mathrm{m}$ and $\beta$ is the required kinetic energy $[10,11]$. The assumed values for $\alpha$ and $\beta$ in the present study are 1 . The residual energy is calculated according to the difference between the initial energy and that consumed after a specific number of movements (subtracting the consumed energy from the initial sensor node energy, which is equal to 10,000 Joule). For simulation, we used the energy consumed after 10 iterations as follows.

$$
{ }^{E} \text { residual }={ }^{E} \text { intital }-{ }^{E} \text { consumed }
$$

This residual energy decreases with each iteration. Briefly, the energy is consumed by the sensor with each communication unit resulting in an increase in the consumed energy. This consumed energy further decreases the level of residual energy of all the sensors.

\section{SIMULATION RESULTS}

\subsection{CaSe STUdy 1 (HELlo MESSAGES)}

The transmission level represents the total unit of transmission (number of times the sensor sends data). The multisink only sends the actual data (one transmission unit every 5 s), while the other approaches send the HELLO package as well as the actual data (two transmission units every $5 \mathrm{~s}$ ).

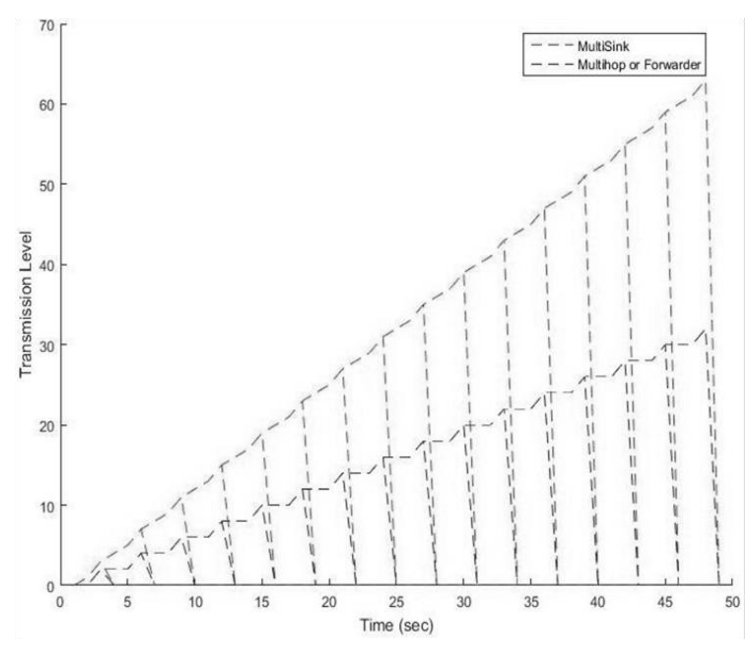

Fig. 4. Results of Total Transmission Unit/S

Figure 4 represents the simulation results for case study 1, which clearly demonstrates that the communication units of HELLO message for multisink is almost half of the multihop and forwarder approaches. The lesser the number of communication units, the lesser energy is consumed resulting in more stability. The multisink approach has better energy consumption per HELLO message transmitted.

\subsection{Case Study 2 (Distance Calculation)}

Table 3 illustrates that the distance between the sensor and sink nodes is minimal in the case of multisink approach as compared to the multihop and forwarder approaches. This distance exhibits that the sensor nodes in the multisink select the sink nodes in proximity data transmission, unlike the other two approaches. This phenomenon saves energy.

\subsection{CaSe STUdy 3 (Residual EnERgy)}

In each movement (represented from 1 to 10 ), all approaches are sending periodic data every 5 s. Multihop and forwarder approaches are sending HELLO messages, as well as, acting 
as a hub to receiving periodic data from other sensors. The initial power level of sensor \#1 is 1875.

TABLE 3: ShorTest Distance BeTweEN SENSOR NODE \#1 AND SINK NODES FOR EACH MOVEMENT

\begin{tabular}{|c|c|c|c|}
\hline TIME/S & MULTIHOP & FORWARDER & MULTISINK \\
\hline 1 & 4.47 & 4.47 & 4.47 \\
\hline 2 & 4.24 & 4.24 & 3.60 \\
\hline 3 & 4.47 & 4.47 & 2.23 \\
\hline 4 & 5.09 & 5.09 & 1 \\
\hline 5 & 6 & 6 & 1 \\
\hline 6 & 7.07 & 7.07 & 2.23 \\
\hline 7 & 8.24 & 8.24 & 3.60 \\
\hline 8 & 9.48 & 9.48 & 5 \\
\hline 9 & 10.77 & 10.77 & 6.40 \\
\hline 10 & 12.08 & 12.08 & 7.81 \\
\hline
\end{tabular}

Sending and receiving data will consume energy, thereby causing a decline in the initial power level. As shown in Figure 3, the multisink approach has the highest level of remaining energy (residual energy) for sensor node \#1 over 10 iterations. A maximum drop in energy for this node was observed in the forwarder approach and a minimum drop in the case of multisink approach. Even though the results show that the multihop has a higher level of residual energy than the forwarder approach, the overall stability of the system is better in the forwarder approach, as the role of the relay node is periodically assigned to all sensor nodes. The results are clearly evident of the fact that the energy consumed in the multisink approach is much lesser than the other two approaches. Thus, Figure 5 presents the sensor node \#1 donning the relay role every $2 \mathrm{~s}$ in the forwarder approach. Moreover, the sensor node \#1 not acting as a relay node in the multihop approach explains the higher residual energy of sensor node \#1 in the multihop approach as compared to the forwarder approach.

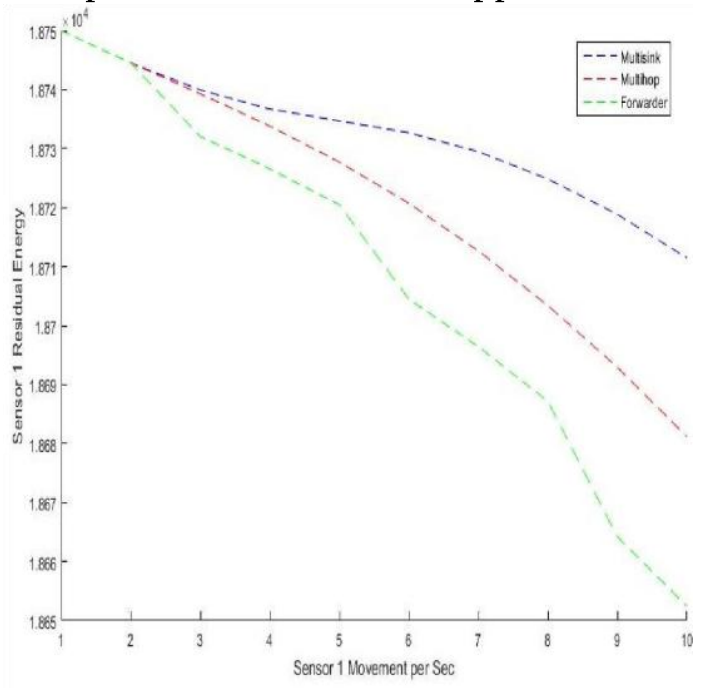

Fig. 5. Sensor 1 Residual Energy per 10 Iterations

\subsection{Case STUdy 4 (SEnsor Lifetime AND System STABILITY)}

As shown in Figure 6, the bar graph represents the total time that each sensor node remained functional. The sensor node is considered to be dead when its energy is exhausted (a low amount of energy is also insufficient to transmit the sensed data).

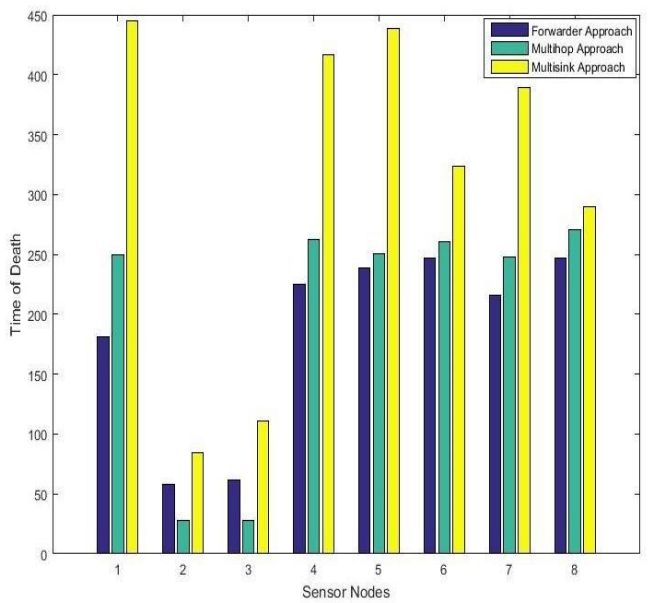

Fig. 6. Sensor Nodes Lifetime and System Stability

The results show that when a sensor node follows the multisink approach, its lifetime increases. On the other hand, when the same sensor node uses the other two approaches, 
multihop and forwarder, the lifetime of the sensor reduces, causing rapid failure of the node. Table 4 displays the time (in s) at which a sensor node dies.

TABLE 4: LIFETIME OF EACH SENSOR NODE (IN S)

\begin{tabular}{|c|c|c|c|}
\hline NODE & $\begin{array}{c}\text { FORWARDER } \\
\text { APPROACH }\end{array}$ & $\begin{array}{c}\text { MULTIHOP } \\
\text { APPROACH }\end{array}$ & $\begin{array}{c}\text { MULTISINK } \\
\text { APPROACH }\end{array}$ \\
\hline$\# 1$ & 181 & 250 & 445 \\
\hline$\# 2$ & 58 & 28 & 84 \\
\hline$\# 3$ & 62 & 28 & 111 \\
\hline$\# 4$ & 225 & 265 & 417 \\
\hline$\# 5$ & 239 & 251 & 439 \\
\hline$\# 6$ & 247 & 264 & 324 \\
\hline$\# 7$ & 216 & 248 & 389 \\
\hline$\# 8$ & 247 & 271 & 290 \\
\hline
\end{tabular}

Table 4 verifies that a sensor node using the multisink approach lasts longer than the same sensor node using the multihop and forwarder approaches. Thus, the multisink approach has longer lifetime per sensor node. This reflects the stability of the network, wherein the energy level is almost relative between sensor nodes in the multisink approach (time of death is relative) as compared to the results of the multihop approach that exhibit the worst network stability. Also, the multisink approach has a better network stability than the forwarder approach.

\section{CONCLUSIONS}

In this study, the multisink approach is introduced to offer energy-efficient routing protocol in the Intra-body communication level of WBAN. The energy consumption is reduced by utilizing three sink nodes and eliminating the role of the relay node in order to avoid energy wastage during data gathering and aggregation. In the multisink approach, the sensor nodes consume energy to transmit the sensed data only. After simulating four case studies, the multisink approach proved to be more energy efficient as compared to the multihop and forwarder approaches. Multisink consumes approximately 50\% less power as compared to the other two approaches as shown in case studies 1 and 2 . Thus, the lifetime of the sensor system was increased by the multisink approach; the sensors were free of an excess burden as they only used energy for sensing data and sending it over the shortest path to the nearest sink node. Moreover, the HELLO message concept is modified in the multisink approach as it eliminates the periodic sending, which in the multihop and forwarder approaches consumes the double amount of energy per total communication unit. By increasing the number of sink nodes, the sensor nodes have the choice of sending data to the nearest sink node directly, and thus, removing the need of relay node. This P2P communication reduces energy consumption and increases the lifetime of sensors, thereby increasing the stability of the overall system.

\section{REFERENCES}

[1] T. G. Zimmerman, "Personal Area Network (PAN)," M.S. thesis, MIT Press, Cambridge, MA, 1995.

[2] M. S. Wegmüller, "Intra-body Communication for Biomedical Sensor Networks", in title of A dissertation submitted to the ETH ZURICH, Diss. ETH No. 1732, 2007.

[3] T. , A. Iyer, D. Tilak, K. Rahate, P. Sawant, "Comparison of Approaches to Intra-body communication", Indian Journal of Computer Science and Engineering (IJCSE), ISSN : 09765166, Vol. 3 No.5, 2012.

[4] S. Adhikary, S. Adhikary, S. Chattopadhyay "A New Routing Protocol for WBAN to Enhance Energy Consumption and Network Lifetime", Proceedings of the 17th International Conference on Distributed Computing and NetworkingACM ICDCN2016, USA.

[5] Raju Sharma, Hardeep Singh Ryait, Anuj Kumar Gupta,"Impact of sink node position in the human body on the performance of WBAN", International Journal of Computer Science and 
Information SecurityIJCSIS, Vol. 14, No. 2, 2016.

[6] P. Juneja, S. Jain," Tree Based Energy Efficient Routing Scheme for Body Area Network", International Conference on Advances in Computer Engineering and ApplicationsICACEA, 2015.

[7] F. Yong, Li Zhaoyuan, Wu Zhou, Sun Yanzan, Du jiechen, "Sink Node Placement Strategy for Wireless Body Area Network", IEEE ICSP2014 Proceedings.

[8] M.M Sandhu, M. Akbar, M. Behzad, N. Javaid, Z. A Khan, U Qasim, "Mobility models for WBANs", Ninth International Conference on Broadband and Wireless Computing, Communication and Applications, 2014.
[9] P. Kinahan," Ultrasound", bioengineering 508, University of Washingtion, 2006.

[10] D. K. Shenkutie, and P. Kumar P. Shinde, "Residual Energy Monitoring in Wirelessn Sensor Networks", Master's Thesis in Embedded and Intelligent Systems, Technical report, IDE1152, 2011.

[11] J. Domingo-Pasual, P. Manzoni, S. Palazzo, A. Pont, and C. Scoglio, "Networking 2011", 10th International Federation for Information Processing Networking Conference (IFIP2011), Spain. 


\title{
بروتوكول التوجيه الفعال لتوجيه الطاقة الموفرة لثبكات الجسد اللاسلكية
}

\author{
ترنيم باريان، أرشييريت كاور، شيلبا شيلبا
}

قسم الهندسة الكهربائية و هندسة الحاسبات، جامعة واترلو، كندا

الملخص:

التقام السريع في شبكة الاستشعار اللاسلكية دعمت بشكل كبير شبكات الجسد اللاسلكية. في شبكات الجسد اللاسلكية وبخاصة في الاستخدامات الطبية تكون نقاط الاستشعار حرجة للغاية لأن نقاط الاستشعار توضع داخل جسم الإنسان، وأنه من الصعب استبدال بطارية أجهزة نقاط الاستشعار. لذلك فإن كفاءة الطاقة هي ركن أساسي في شبكات الجسد اللاسلكية خصوصا في عملية الاتصال داخل الجس، حيث يحدث تواصل بين نقاط الاستشعار (التي يتم وضعها داخل الأنسجة البشرية) ونقاط التجميع (التي يتم وضعها علي الجلد البشري). و هناك العديد من الأبحاث أجريت علي مستوى الاتصال الداخلي بهذف الحد من استهلاك الطاقة عن طريق تقليل المسافة المطلوبة لإرسال بيانات الاستشعار. ومع ذلك، لا يتحقق استقرار النظام (عر النظام الكلي)وذلك بسبب الاختلاف في عمر نقاط الاستشعار. هنا بعض نقاط الاستشعار يجب أن تكون بمثابة النقاط التتابعية. هذه النقاط التتابعية هي نقاط الاستشعار المسؤولة عن الاستشعار عن بعد وكذللك استقبال وتجميع بيانات الاستشعار من نقاط الاستشعار المجاورة. تتابع نقاط الاستشعار هذه يزيد من إرسال البيانات المجمعة إلى نقطة التجميع. في هذا البحث تم عرض طريقة فريدة لتحقيق كفاءة الطاقة وذللك باستخدام بروتوكول التوجيه الفعال الذي يضمن أطول استشعار مدى الحياة، وبالإضافة إلي ذلك استقرار النظام وعلاوة على ذلك، تأخذ الورقة بعين الاعتبار مبدأ الند للند للتواصل بين نقاط الاستشعار ونقاط التجميع عند النظر في نموذج التنقل. في الأساس، يهذف هذا البحث بشكل أساسي إلى إزالة العبء عن نقاط الاستشعار باستخدام نقاط التجميع المتعددة لتحقيق أقصر مسافة للاتصال بين نقاط الاستشعار ونقاط التجميع لإرسال البيانات، والتي تساعد في إطالة عمر نقاط الاستشعار وكذلك الاستقرار الثامل للنظام. 